\title{
A QUANTITATIVE METHOD TO EXAMINE THROUGH THICKNESS TEXTURE VARIATION
}

\author{
S. SAIMOTO, R. G. KAMAT and P. CLARKE \\ Dept. of Materials and Metallurgical Engineering, Queen's University, Kingston, \\ Ontario, K7L 3N6, Canada \\ P. VAN HOUTTE \\ Dept. of Metallurgy and Materials Engineering, Katholieke Universiteit Leuven, \\ de Croylaan 2, B3001 Heverlee, Belgium
}

(Received May 20, 1992; in final form August 3, 1992)

\begin{abstract}
Through thickness texture variation is a reality in commercial sheet stock. However, methods to quantitatively evaluate this variation and its effects are not readily available. In this study, it was shown that a hot rolled commercial aluminium sheet manifests variation in rolling texture components which can be detected by traverse scan of the peak intensity across the through thickness using tapered specimens. Moreover, this asymmetry can be correlated to the intensity asymmetry observed in pole figures. A quantitative analysis is possible if the ODF is generated using monoclinic symmetry with the transverse direction as the diad axis instead of the conventional orthorhombic symmetry.
\end{abstract}

KEY WORDS Pole figures, orientation distribution functions, through thickness texture variation, orthorhombic symmetry, monoclinic symmetry.

\section{INTRODUCTION}

The through thickness texture variations in the as-rolled sheets have been observed (Wassermann and Grewen, 1962) sometime ago but their consequence on annealing texture and the resultant mechanical properties has been largely ignored. The origin of texture inhomogeneities under cold rolling conditions was systematically studied by Asbeck and Mecking (1978) using copper single crystals. They showed that the most important parameter was the ratio of the length of the contact between the role and the sample to the thickness of the sample. If this ratio was smaller than 0.5 severe inhomogenities in the through thickness texture developed. In the initial roughing stages of industrial hot rolling such situations may exist, but in the later stages of the tandem mill, conditions are such that this ratio is very high and the through thickness texture variation is expected to be minimal. To avoid obviously layered textures with unexpected deformation patterns (Brown, 1985, Naess, 1990), most of the texture examinations in the laboratory processed sheets are performed on the mid-sections as described in recent reviews (Hirsch, 1986, Hutchinson, Ekstrom, 1990). Current emphasis on study of industrially processed products has given rise to a phenomenon which has hitherto been attributed to the inadequacies of the data acquisition system during pole figure determination. This phenomenon of unequal intensities in the 
maximum peak positions, even though the pole figure pattern has a recognizable orthorhombic symmetry, will be shown to have a true physical basis. Process engineers have tried to integrate such manifestations of inhomogenities by using an averaging procedure such as using cross-sections from laminated sheets for $\mathrm{X}$-ray analysis. Such techniques are useful as quality control measures but may not be ideal to study quantitatively the evolution of texture. To optimize the current metal processing practice, the precise through thickness texture has to be evaluated for plant specific rolling equipment and conditions. Hence, new methods to assess the through thickness texture variations are required.

The purpose of this paper is to demonstrate that the through thickness texture variation can be quantitatively represented section by section if it is realized that the pole figures do not necessarily manifest orthorhombic symmetry in intensities although their patterns may suggest so. Examination of this intensity asymmetry indicates that a monoclinic symmetry axis may exist. Such symmetry can be processed using Orientation Distribution Function (ODF) software developed by Van Houtte (1984).

\section{EXPERIMENTAL WORK}

Industrially processed coils of alloy AA3004 whose composition is shown in Table 1 were used in this study. The details of as-received hotband $\dagger$ and subsequent annealing characterization are described in detail elsewhere (Saimoto, Kamat, 1992, Kamat, Saimoto, 1992). The $2.3 \mathrm{~mm}$ thick hotband samples with exit temperatures of $351^{\circ} \mathrm{C}$ (series 7 ) and $323^{\circ} \mathrm{C}$ (series 3) were obtained by widening the trimming knives to $120 \mathrm{~mm}$ and quenching these slabs in water within one minute after exit from the tandem mill. Metallographic specimens of the size $10 \mathrm{~mm} \times 15 \mathrm{~mm}$ were ground, polished and lightly etched to obtain 1/4 thickness position on each side of the same specimen. From these specimens (111), (200), (311) and (210) pole figures were determined using a rotating copper-anode X-ray facility described elsewhere (Saimoto et al., 1990). Taper sections of $5^{\circ}$ were prepared to perform edgewise traverse scan of $1 \mathrm{~mm} \times 10 \mathrm{~mm} X$-ray beam in steps of $0.25 \mathrm{~mm}$ every $4 \mathrm{~s}$ (Saimoto, Kamat, 1992, Saimoto, 1988) on both side 1 and side 2 as shown in Figure 1. Such scans produce a through thickness intensity profile of a given reflection, typically (111) is used for as-rolled and (200) for the partially recrystallized case.

Table 1 Chemical composition of the alloy used in the study

\begin{tabular}{lllllllll}
\hline Element & $M n$ & $M g$ & $F e$ & $S i$ & $C u$ & $Z n$ & $T i$ & $A l$ \\
\hline In wt. \% & 1.009 & 1.180 & 0.399 & 0.196 & 0.152 & 0.065 & 0.036 & Rest \\
\hline
\end{tabular}

† Hotband or re-roll refers to a coiled aluminium sheet which has been hot rolled in a tandem mill. 


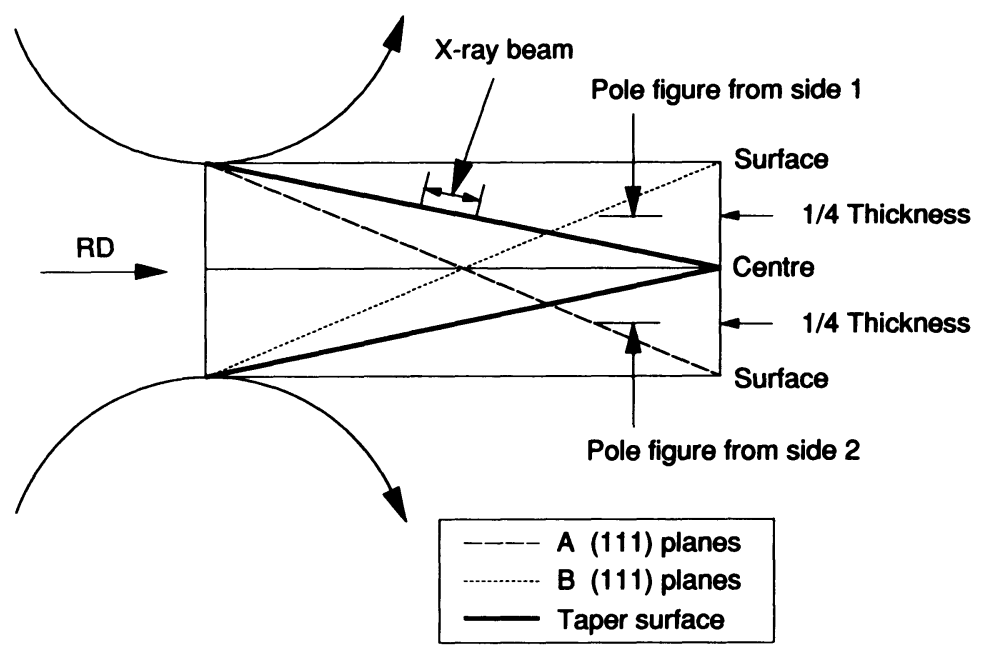

Figure 1 Schematic diagram depicting the (111) diffraction planes, the tapered sections with respect to sides 1 and 2 , and the orientation of the pole figure section at 1/4 thickness. Retention of this geometry permits the confirmation of any observed asymmetry between planes $\mathbf{A}$ and $\mathbf{B}$.

\section{RESULTS AND DISCUSSION}

The taper section (111) scans shown in Figures 2 and 3 illustrate that the intensities of the two supposedly equivalent reflections are not the same throughout the thickness. In fact, a large asymmetry exists near the 1/4 thickness level. The differences in the through thickness texture from one side of sheet to the other about the centre may reflect different conditions of the top and bottom rolls, and how the lubricant was added. This suggests that to obtain a truly homogeneous strip it is necessary to have steady state operating conditions across the width and throughout the length of the coil. The intensity difference shown in Figures 2 and 3 was confirmed by the appearance of an intensity asymmetry in the (111) pole figures as shown in Figure 4. This asymmetry in the through thickness texture can be better clarified with the aid of schematic diagram shown in Figure 1. As can be seen, at the $1 / 4$ thickness levels in the top and bottom halves of the sheet the high intensity (111) poles show an asymmetry. This asymmetry suggests preferential shearing on one set of planes in the top half and the mirror image equivalent ones in the bottom half. Such intensity variations of the order of factor of two or more in AA3004 have also been reported by others (Merchant and Morris, 1990) but without discussion. Since the intensities have similar values for reflections both at the surface and the centre (Figures 2 and 3), the geometry of plastic flow must primarily account for this intensity asymmetry rather than the expected temperature gradient between the surface and the centre. The microstructural origin of this phenomenon should manifest itself as a chevron pattern in 

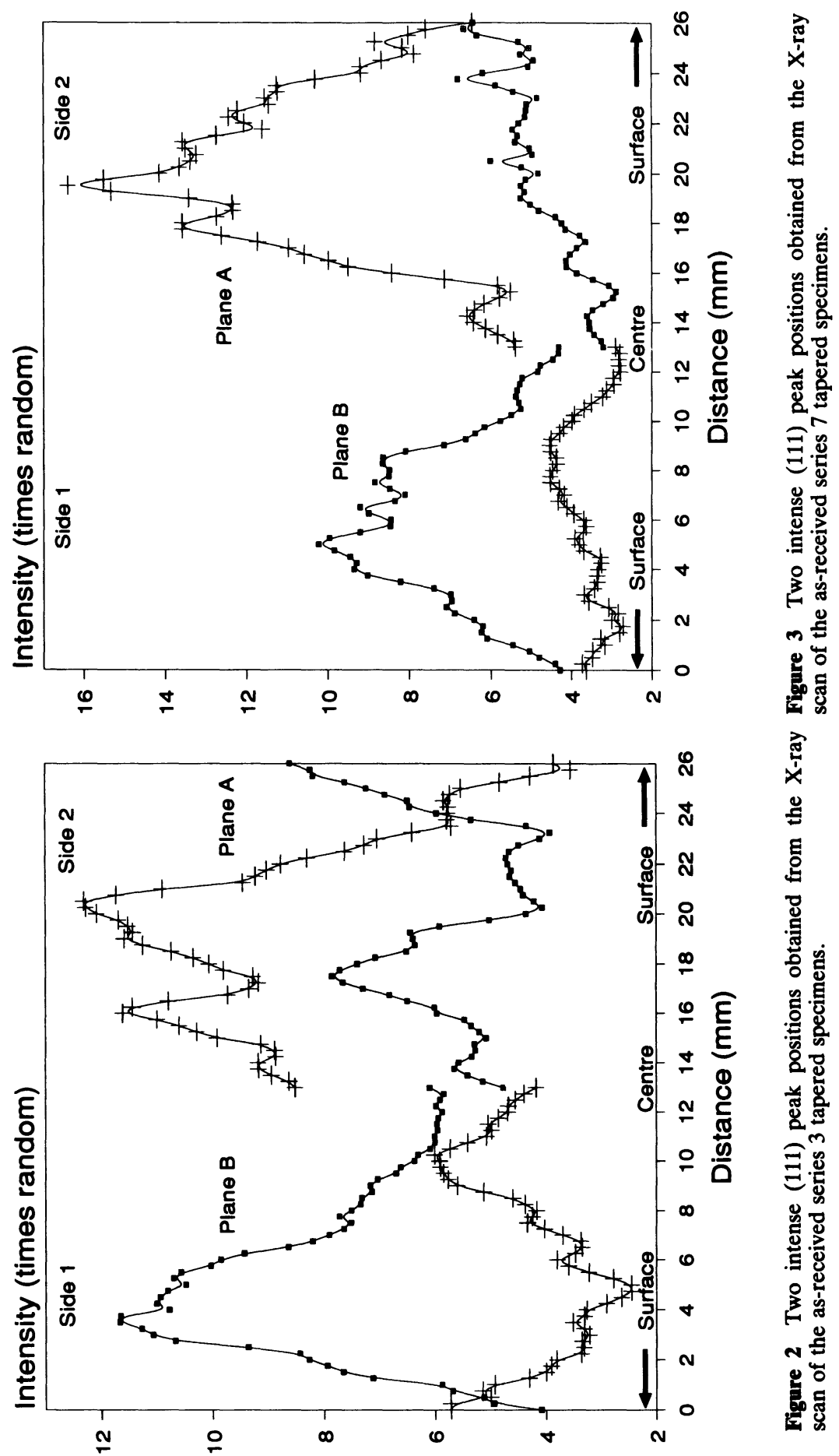


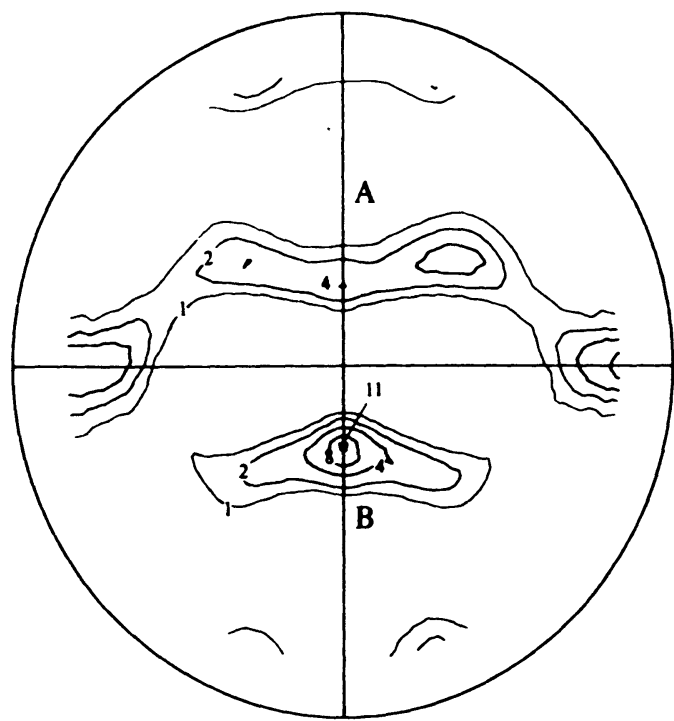

(a)

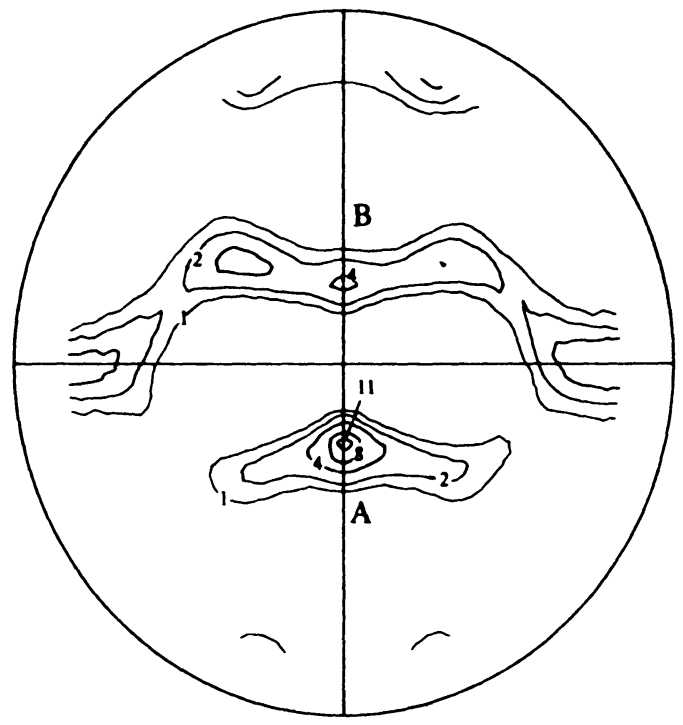

(b)

Figure 4 (111) Pole figures obtained at the 1/4 thickness of the as-received series 3 hotband (a) side 1 and (b) side 2 .

the metallographic section perpendicular to the transverse direction. Electron channelling contrast examination of such sections were not definitive suggesting that the strain gradients are too diffuse to be detected by this method. Transmission electron microscopy may reveal systematic dislocation density differences if small scale microbands are not directly evident.

The through thickness texture asymmetry indicates the inadequacy of applying the orthorhombic symmetry for calculating the ODF. Hence to analyze the pole 


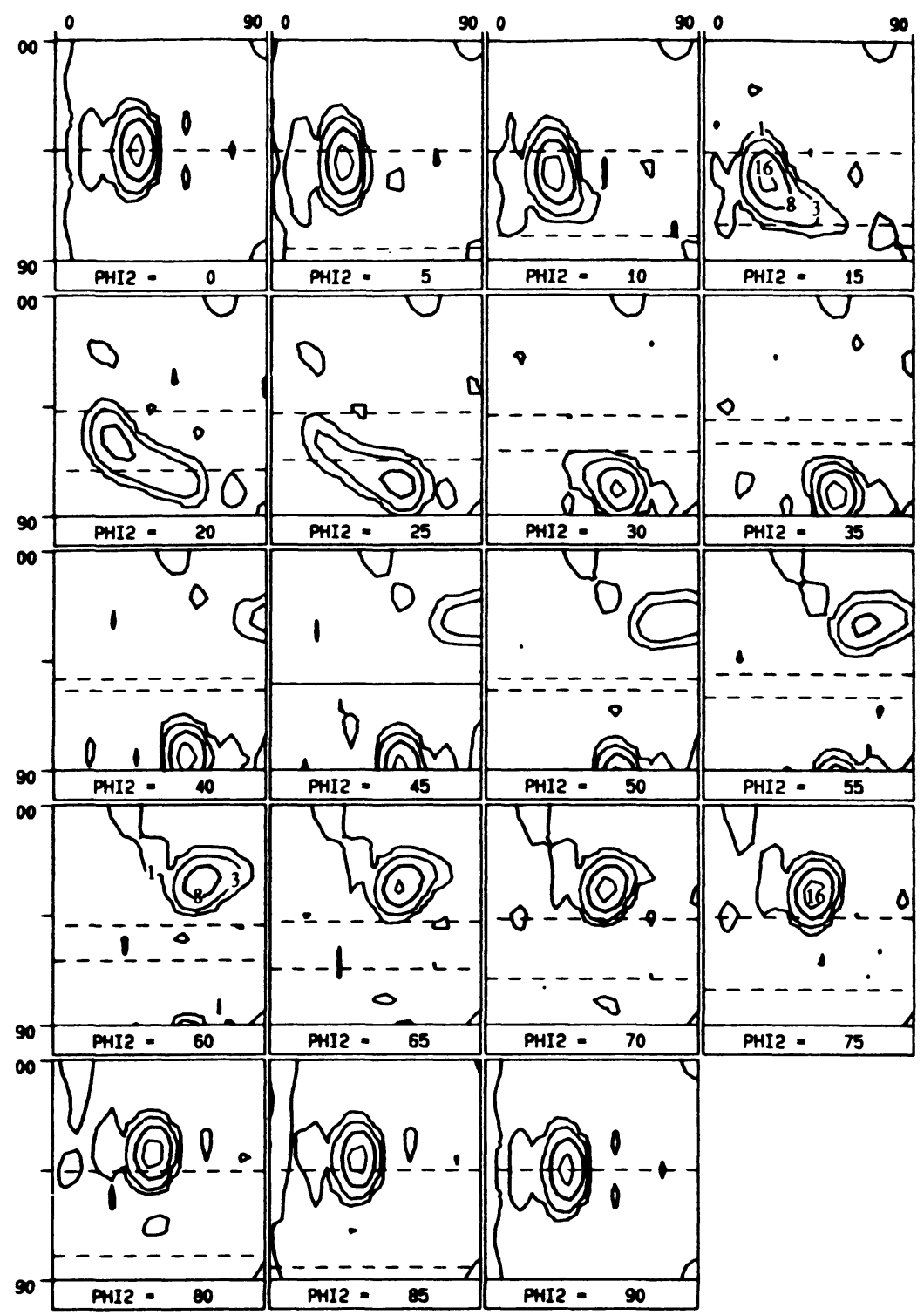

Figure 5 Orientation Distribution Function (ODF) diagram calculated for the 1/4 thickness position (side 1) of the as-received series 3 hotband assuming orthorhombic symmetry.

figures using ODF the standard orthorhombic symmetrization was compared to that using monoclinic with the diad axis parallel to the $\mathrm{TD}$, that is $X_{2}$ in conventional ODF notation. The ODFs are shown in Figures 5 and 6. From an application viewpoint, calculation of the volume fractions from the $C$ coefficients is most informative. Volume fractions were calculated from ideal orientations using $\phi_{0}=11^{\circ}$ Gaussian distributions. The Euler angles of the orientations used 


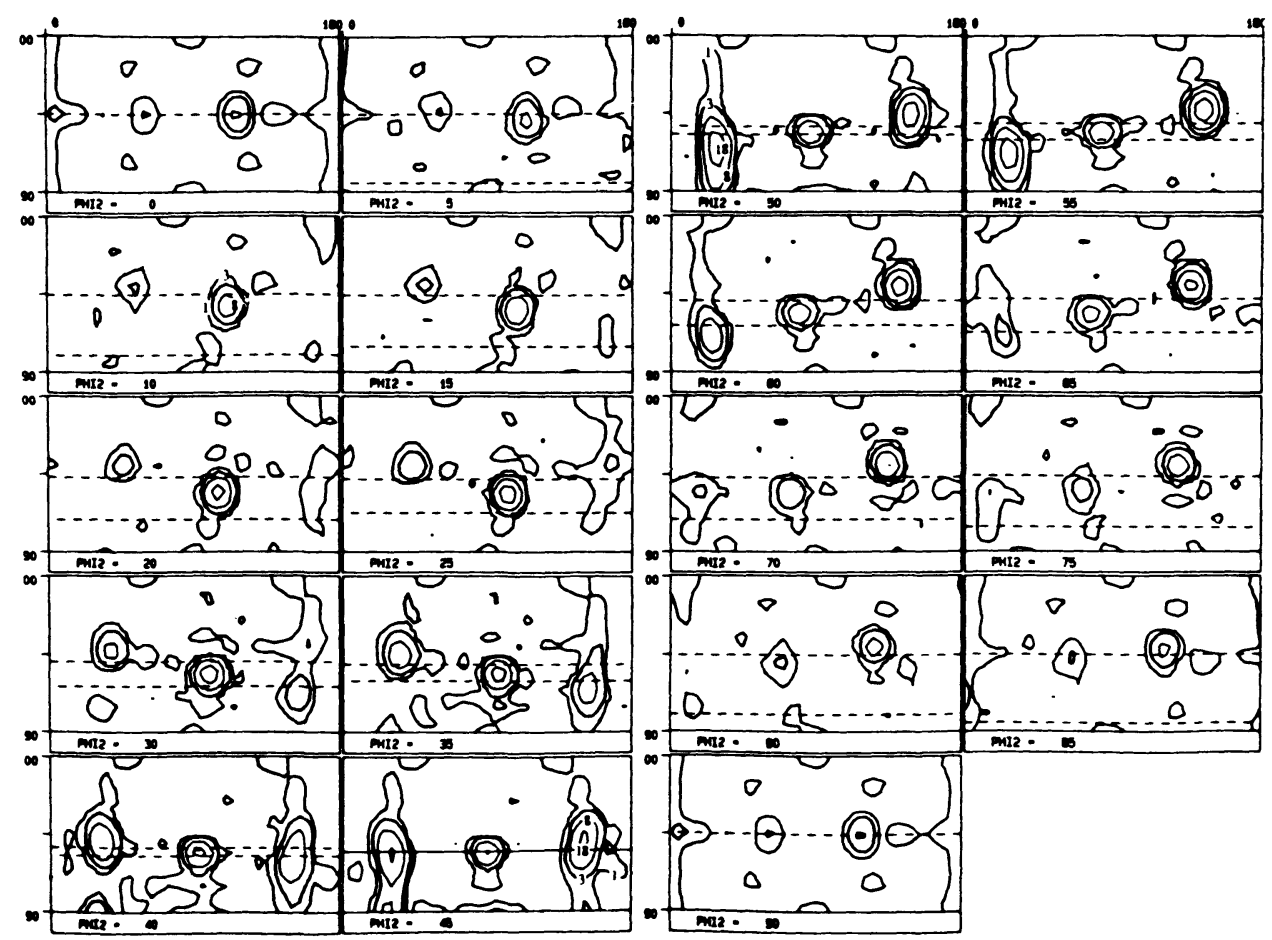

Figure 6 Orientation Distribution Function (ODF) diagram calculated for the 1/4 thickness position (side 1) of the as-received series 3 hotband assuming monoclinic symmetry.

Table 2 Euler angles of the orientations used in the calculation of ODF data for monoclinic symmetry

\begin{tabular}{lccc}
\hline $\begin{array}{l}\text { Texture components in } \\
\text { monoclinic indices }\end{array}$ & \multicolumn{3}{c}{ Corresponding Euler angles $\left(^{\circ}\right)$} \\
\cline { 2 - 4 } & $\phi_{1}$ & $\phi$ & $\phi_{2}$ \\
\hline Cube $(0 \overline{10})[100]$ & 180 & 90 & 90 \\
Goss $(01 \overline{1})[100]$ & 90 & 90 & 45 \\
Brass $(\overline{11})[2 \overline{11}]$ & 54.7 & 90 & 45 \\
$\mathrm{~S}\{123\}\langle 634\rangle$ & & & \\
$\mathrm{S}_{3}^{\prime}(123)[6 \overline{4}]$ & 32.6 & 72.1 & 52.3 \\
$\mathrm{~S}_{3}^{\prime \prime}(123)[\overline{634}]$ & 147.4 & 72.1 & 37.7 \\
$\mathrm{Cu}\{112\}\langle 111\rangle$ & & & \\
$\mathrm{Cu}(112)[\overline{11} 1]$ & 144.7 & 90 & 45 \\
$\mathrm{Cu}(112)[11 \overline{1}]$ & 35.3 & 90 & 45 \\
$\mathrm{H}(\overline{110})[110]$ & 135 & 90 & 90 \\
$\mathrm{CG}(\overline{0} 1)[100]$ & 90 & 90 & 26.6 \\
$\mathrm{CH}(\overline{120})[210]$ & 153.4 & 90 & 90 \\
\hline
\end{tabular}


Table 3 Volume percent of texture components calculated from ODF data using orthorhombic and monoclinic symmetries for sides 1 and 2 of as-received series 3 and series 7 specimens

\begin{tabular}{|c|c|c|c|c|c|c|c|c|c|}
\hline \multirow[t]{3}{*}{$\begin{array}{l}\text { Texture } \\
\text { components }\end{array}$} & \multicolumn{4}{|c|}{$\begin{array}{l}\text { Orthorhombic } \\
\text { (Vol. \%) }\end{array}$} & \multirow[t]{3}{*}{$\begin{array}{l}\text { Texture } \\
\text { components }\end{array}$} & \multicolumn{4}{|c|}{$\begin{array}{l}\text { Monoclinic } \\
\text { (Vol. \%) }\end{array}$} \\
\hline & \multicolumn{2}{|c|}{ Series 3} & \multicolumn{2}{|c|}{ Series 7} & & \multicolumn{2}{|c|}{ Series 3} & \multicolumn{2}{|c|}{ Series 7} \\
\hline & Side 1 & Side 2 & Side 2 & Side 2 & & Side 1 & Side 2 & Side 1 & Side 2 \\
\hline Cube (001)[100] & 0.98 & 0.84 & 1.10 & 0.97 & Cube (010)[100] & 0.99 & 0.86 & 1.17 & 0.99 \\
\hline Goss (011)[100] & 1.14 & 0.84 & 0.91 & 1.09 & Goss $(01 \overline{1})[100]$ & 1.21 & 1.02 & 1.09 & 1.26 \\
\hline Brass $\{011\}\langle 211\rangle$ & 16.93 & 16.28 & 21.46 & 15.44 & Brass $(\overline{11} 1)[2 \overline{1} 1]$ & 16.18 & 15.73 & 20.00 & 15.01 \\
\hline \multirow[t]{3}{*}{$S\{123\}\langle 634\rangle$} & 25.40 & 26.78 & 24.04 & 24.57 & $S\{123\}\langle 634\rangle$ & 24.26 & 25.76 & 22.35 & 23.86 \\
\hline & & & & & $S_{3}^{\prime}(123)[63 \overline{4}]$ & 16.23 & 9.07 & 13.74 & 10.75 \\
\hline & & & & & $S_{3}^{\prime \prime}(123)[\overline{634}]$ & 8.03 & 16.69 & 8.61 & 13.11 \\
\hline \multirow[t]{3}{*}{$\mathrm{Cu}\{112\}\langle 111\rangle$} & 5.43 & 6.32 & 4.64 & 10.02 & $\mathrm{Cu}\{112\}\langle 111\rangle$ & 5.13 & 6.09 & 4.40 & 9.71 \\
\hline & & & & & $\mathrm{Cu}^{\prime}(112)[\overline{11} 1]$ & 3.76 & 1.66 & 3.29 & 4.74 \\
\hline & & & & & $\mathrm{Cu}^{\prime \prime}(112)[11 \overline{1}]$ & 1.37 & 4.43 & 1.11 & 4.97 \\
\hline$H(001)[110]$ & 0.11 & 0.18 & 0.39 & 0.29 & H (110)[110] & 0.18 & 0.24 & 0.46 & 0.32 \\
\hline CG (021)[100] & 1.67 & 1.49 & 2.01 & 1.78 & CG (02) 1$)[100]$ & 1.72 & 1.56 & 2.16 & 1.90 \\
\hline $\mathrm{CH}(001)[120]$ & 0.35 & 0.36 & 0.58 & 0.43 & $\mathrm{CH}(\overline{120})[210]$ & 0.42 & 0.45 & 0.56 & 0.75 \\
\hline
\end{tabular}

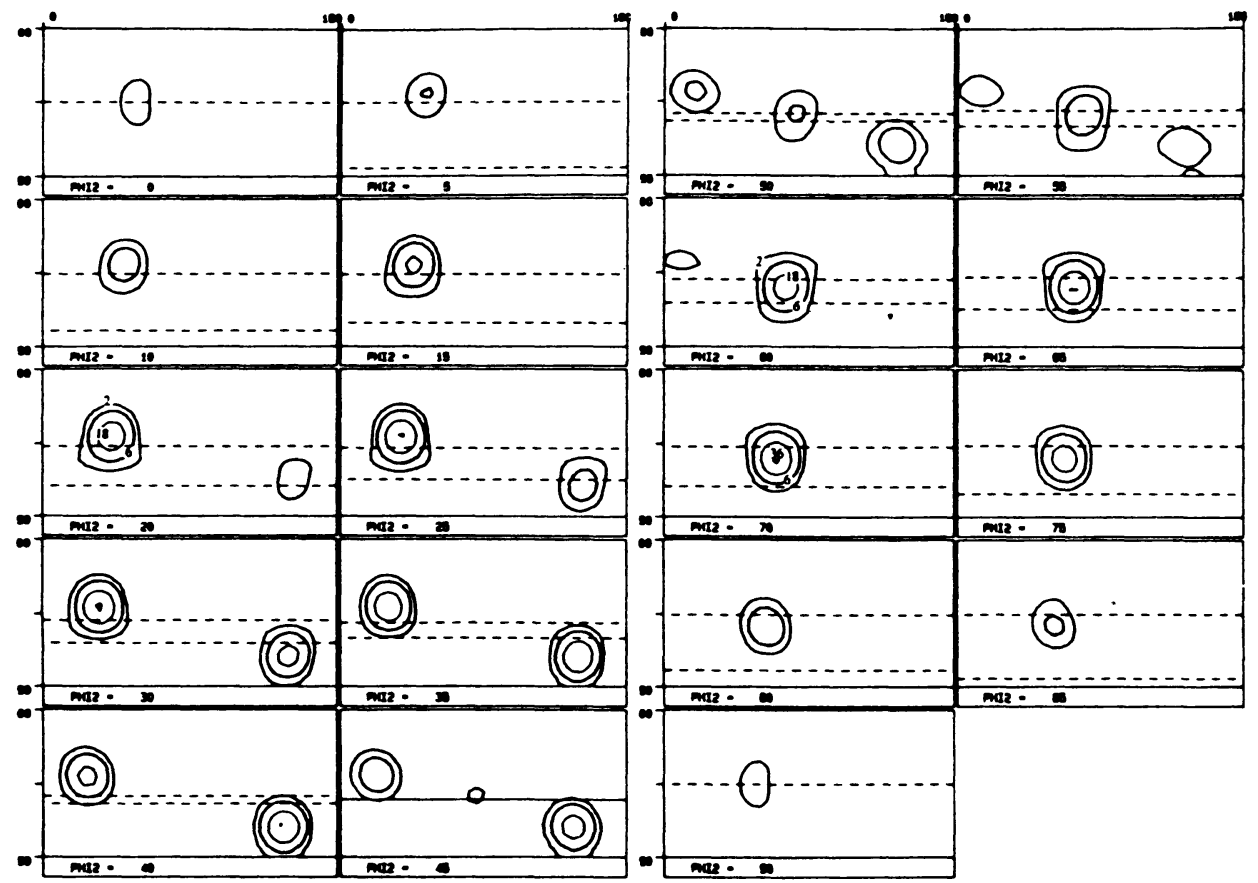

Figure 7 Orientation Distribution Function (ODF) diagram calculated for the model function $S_{3}^{\prime \prime}$ assuming monoclinic symmetry with Gaussian distribution of $\phi_{0}=11^{\circ}$. 
in the calculations of ODF data for monoclinic symmetry are listed in Table 2. Series 3 and 7 specimen volume fractions of texture components for orthorhombic and monoclinic symmetries are compared in Table 3 . In the case of monoclinic symmetrization the $\mathrm{S}$ and $\mathrm{Cu}$ texture components consist of two sub-components each $\left(\mathrm{S}_{3}^{\prime}, \mathrm{S}_{3}^{\prime \prime}\right.$ and $\left.\mathrm{Cu}^{\prime}, \mathrm{Cu}^{\prime \prime}\right)$ representing the asymmetries of the main components. The sum of the volume fractions of these sub-components in each case should be numerically equal to that for orthorhombic symmetry case as shown in Table 3 . However, as indicated in Table 3 the volume fractions of the $\mathrm{S}$ and $\mathrm{Cu}$ components for the orthorhombic case are slightly higher than the sum of the sub-components for the monoclinic case. These and other deviations in the remaining texture components are attributed to the computational errors in the pole figure analyses using the two schemes. The $S_{3}^{\prime \prime}$ model function in Figure 7 when compared to Figure 6 shows that $S_{3}^{\prime \prime}$ is the minor component to $S_{3}^{\prime}$ as confirmed in Table 3. The histograms shown in Figures 8 and 9 compare the variations in volume fractions predicted for orthorhombic and monoclinic symmetrization respectively. The symmetrical texture components show only the computational deviations in the volume fractions vis-a-vis monoclinic symmetrization due to the fact that the inherent multiplicity masks the asymmetrical distribution of crystal orientations. This study illustrates as to why the stacked layer averaging method for specimen preparation results in orthorhombic pole figures. However, such data may be misleading when considering origin of

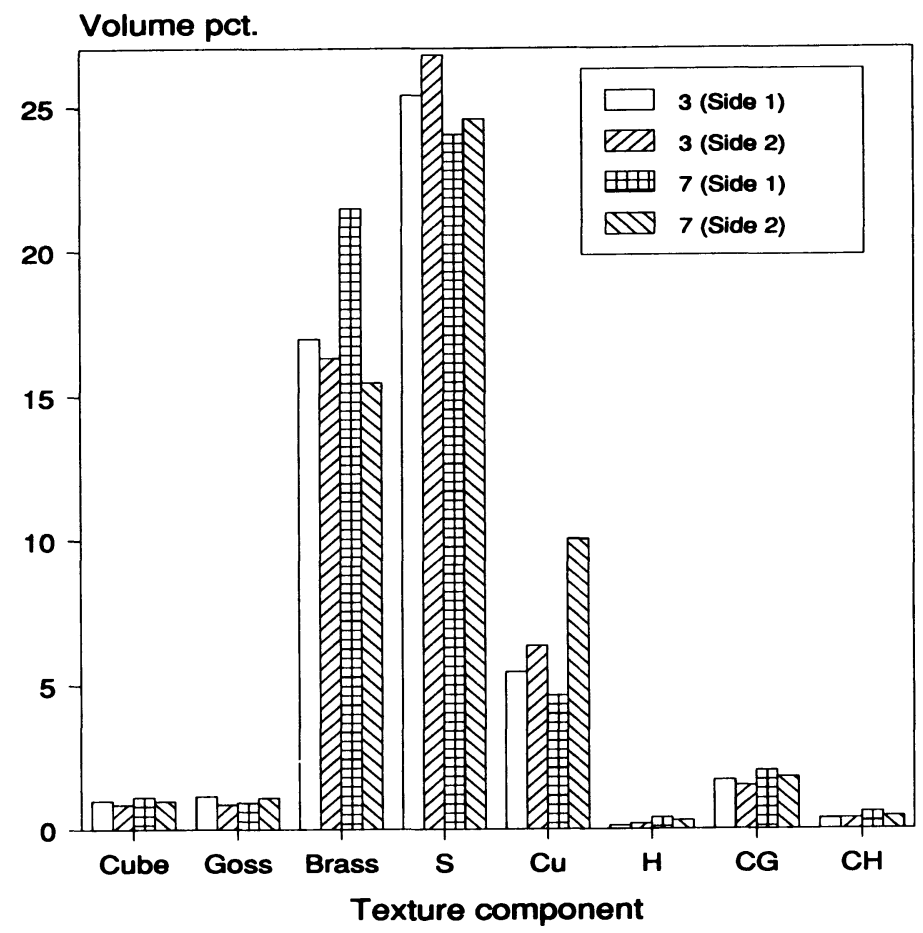

Figure 8 Volume percent of texture components calculated from the ODF data using orthorhombic symmetry for sides 1 and 2 of as-received series 3 and series 7 specimens. 


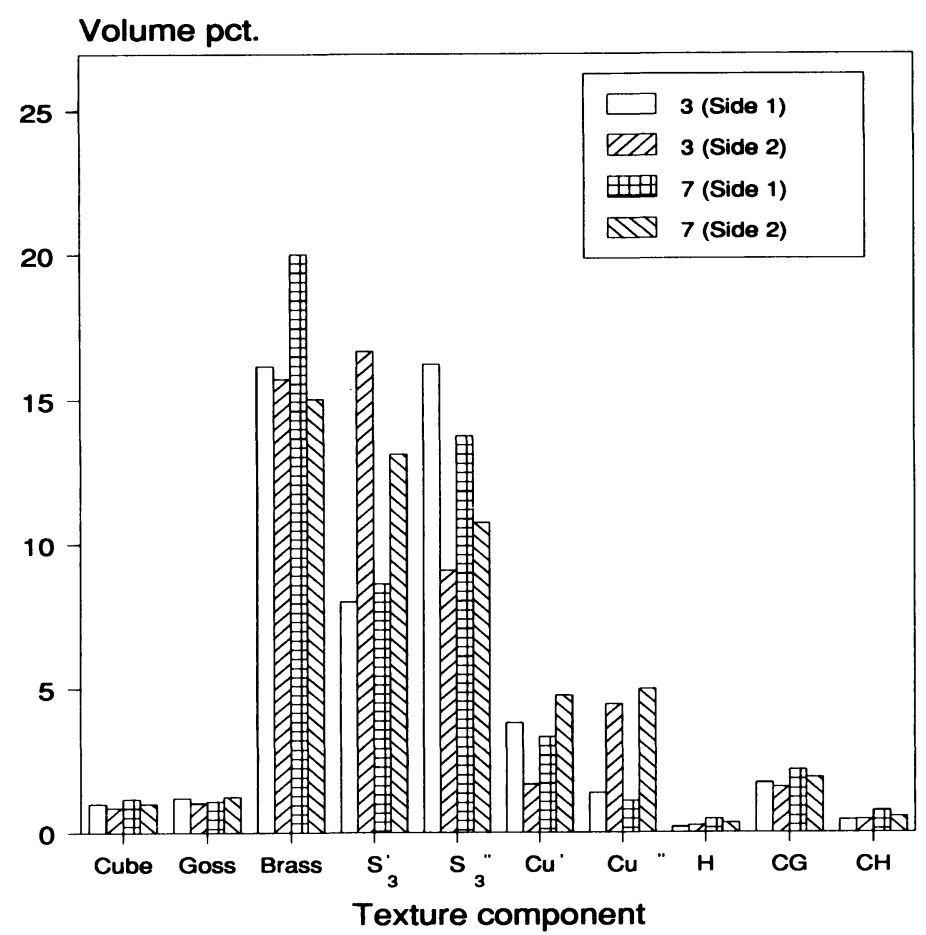

Figure 9 Volume percent of texture components calculated from the ODF data using monoclinic symmetry for sides 1 and 2 of as-received series 3 and series 7 specimens.

recrystallization sites. Comparison of the volume fraction of $S_{3}^{\prime}$ and $S_{3}^{\prime \prime}$ components and those corresponding to $\mathrm{Cu}^{\prime}$ and $\mathrm{Cu}^{\prime \prime}$ reflect the asymmetry expected from the pole figures (Figure 4). Moreover, the localized shearing during hot rolling so dramatically illustrated microstructurally by Sakai et al. (1987) can be quantitatively examined by this analysis.

Evolution of the intensity asymmetry during commercial rolling may be attributed to the unidirectional orientation of the sheet with respect to the rolls during the tandem mill operation. In contrast during laboratory rolling the slab is rotated about the sheet normal or flipped over after each pass. The herring bone pattern of the texture indicates that it is induced by the rolls although Hjelen and Nes's (1987) observations that the cube oriented grains occur in the transition bands (Dilamore and Katoh, 1974) between two mirror components of $\{112\}\langle 111\rangle(\mathrm{Cu})$ orientation may still apply. A more definitive mechanism for promoting nucleation of cube grains in regions of greatest intensity asymmetry as suggested by Figures 2 and 3 needs examination. Thus, studies similar to Hjelen and Nes (1987), and Ridha and Hutchinson (1982) are required to further the understanding of the genesis of cube texture. However, from a practical viewpoint of optimizing the hot rolling process for a specific mill, traverse X-ray scan and through thickness ODF analyses using monoclinic symmetry can be very useful. 


\section{CONCLUSIONS}

The standard ODF analysis which imposes orthorhombic symmetry of the pole figures may give rise to misinterpretation if an intensity asymmetry exists in the pole figures. Quantitative assessment of texture evolution especially during recrystallization can be made by applying the less restrictive assumption of monoclinic symmetry with diad axis parallel to TD. This approach should provide more reliable results and permit systematic study of through thickness texture evolution.

\section{ACKNOWLEDGEMENTS}

The authors thank the Ontario Centre for Materials Research, Natural Science and Engineering Research Council, and Alcan International Ltd. for financial support. We are most grateful to Alcan Rolled Products Ltd. for continued supply of material and exchange of information.

\section{References}

Asbeck, H. O. and Mecking, H. (1978). Influence of friction and geometry of deformation on texture inhomogeneities during rolling of $\mathrm{Cu}$ single crystals as an example. Mater. Sci. Eng. 34, 111-119.

Brown, K. R. (1985). Factors affecting texture development in rolled aluminum alloys. In Textures in non-ferrous metals and alloys, (ed. H. D. Merchant and J. G. Morris), 17-44.

Dilamore, I. L. and Katoh, H. (1974). The mechanisms of recrystallization in cubic metals with particular reference to their orientation-dependence. Metal Science Journal 8, 73-83.

Hirsch, J. (1986). Recrystallization of FCC metals as investigated by ODF analysis. In Annealing Processes-Recovery, Recrystallization and Grain Growth, (eds. N. Hansen, D. Juul Jensen, T. Leffers and B. Ralph), 7th Riso International Symposium, Riso, Denmark 349-360.

Hjelen, J. and Nes, E. (1987). The evolution of recrystallization textures in aluminium as examined by electron back scattering patterns. In Textures of Materials, Proc. ICOTOM 8, (eds. J. S. Kallend and G. Gottstein), Warrendale, PA, The Metallurgical Society of AIME, 597-602.

Hutchinson, W. B. and Ekstrom, H-E. (1990). Control of annealing texture and earing in non-hardenable aluminium alloys. Mater. Sci. Technol., 6, 1103-1111.

Kamat, R. G. and Saimoto, S. (1992). Quantitative assessment of microstructure and texture in a hot rolled aluminium alloy, In Aluminium Alloys, Their Physical and Mechanical Properties, Vol. II, (eds. L. Arnberg, O. Lohne, E. Nes and N. Ryum), 291-296, 3rd International Conference on Aluminium Alloys, June 1992, The Norwegian Institute of Technology, Dept. of Metallurgy and SINTEF Metallurgy, Trondheim, Norway.

Merchant, H. D. and Morris, J. G. (1990). Annealing response of 3000 and 5000 series aluminium alloys. Metall. Trans. A, 21A, 2643-2654.

Naess, S. E. (1990). Evolution of recrystallization textures in the aluminium alloys AA3005 and AA5050. In Recrystallization '90, (ed. T. Chandra), 193-198, Warrendale, PA, The Metallurgical Society of AIME.

Ridha, A. A. and Hutchinson, W. B. (1982). Recrystallization mechanisms and the origin of cube texture in copper. Acta Metall., 30, 1929-1939.

Saimoto, S. (1988). Microstructural and textural evolution during hot rolling of $\mathrm{Al}-\mathrm{Mg}$ alloys. In Physical simulation of welding, hot forming and continuous casting, (ed. J. W. Bowker), CANMET Pub. In press.

Saimoto, S. and Kamat, R. G. (1992). Microstructure and texture evolution in hot rolled AA3004 aluminium alloy, Materials Science and Technology, In press.

Saimoto, S., Van Houtte, P., Clarke, P. and Reesor, D. (1990). Textural evolution during draw-cup tests of thick aluminium 3004 alloy sheet. In Textures and Microstructures, Proc. ICOTOM 9, (eds. R. Penelle and C. Esling), 14-18, 1237-1238. 
Sakai, T., Saito, Y. and Kato, K. (1987). Recrystallization and texture formation in high speed hot rolling of austenitic stainless steel. Trans. ISIJ, 27, No. 6, 520-525.

Van Houtte, P. (1984). A new method for the determination of texture functions from incomplete pole figures-comparison with older methods. Textures and Microstructures, 6, 137-162.

Wassermann, G. and Grewen, J. (1962). In Texturen metallischer Werkstoffe II, Aufl. Springer Verlag, Berlin, 273. 